\title{
Positive Technology: Using Interactive Technologies to Promote Positive Functioning
}

\author{
Giuseppe Riva, Ph.D., ${ }^{1,2}$ Rosa M. Baños, Ph.D., ${ }^{3,4}$ Cristina Botella, Ph.D.,, ${ }^{4,5}$ \\ Brenda K. Wiederhold, Ph.D., M.B.A., BCIA, ${ }^{6,7}$ and Andrea Gaggioli, Ph.D., ${ }^{1,2}$
}

\begin{abstract}
It is generally assumed that technology assists individuals in improving the quality of their lives. However, the impact of new technologies and media on well-being and positive functioning is still somewhat controversial. In this paper, we contend that the quality of experience should become the guiding principle in the design and development of new technologies, as well as a primary metric for the evaluation of their applications. The emerging discipline of Positive Psychology provides a useful framework to address this challenge. Positive Psychology is the scientific study of optimal human functioning and flourishing. Instead of drawing on a "disease model" of human behavior, it focuses on factors that enable individuals and communities to thrive and build the best in life. In this paper, we propose the "Positive Technology" approach-the scientific and applied approach to the use of technology for improving the quality of our personal experience through its structuring, augmentation, and/or replacement-as a way of framing a suitable object of study in the field of cyberpsychology and human-computer interaction. Specifically, we suggest that it is possible to use technology to influence three specific features of our experience-affective quality, engagement/actualization, and connectedness-that serve to promote adaptive behaviors and positive functioning. In this framework, positive technologies are classified according to their effects on a specific feature of personal experience. Moreover, for each level, we have identified critical variables that can be manipulated to guide the design and development of positive technologies.
\end{abstract}

\section{Introduction}

THFORMATION AND COMMUNICATION TECHNOLOgIES are becoming more present in people's daily lives. But what is the purpose of the mass proliferation of digital devices? Are they helpful in fostering personal growth and individual integration in the sociocultural environment, by promoting satisfaction, opportunities for action, and self-expression? Do they rather enhance automation, constraints on personal initiative, and compulsive consumption of information?

In this paper, we suggest that one of the fundamental objectives for our field-cyberpsychology - in the coming decade will be to create technologies that contribute to enhancement of happiness and psychological well-being. ${ }^{1}$

In the human-computer interaction (HCI) field, some scholars are also starting to recognize this challenge. For ex- ample, Zhang and colleagues ${ }^{2}$ suggest that HCI has moved from addressing the basic needs and goals of users toward supporting higher-level human needs and goals. Taking a holistic perspective, these authors call for research that examines the impact of technologies on individuals' personal growth and self-actualization. ${ }^{3}$ More recently, Sander ${ }^{4(\mathrm{p} 311)}$ defined "Positive Computing" as "the study and development of information and communication technology that is consciously designed to support people's psychological flourishing in a way that honors individuals' and communities' different ideas about the good life."

The emerging discipline of Positive Psychology, which focuses on the bio-psycho-social aspects of cognitions, emotions, and positive experiences, ${ }^{5,6}$ provides a useful framework for guiding our efforts. Positive Psychology can suggest how to develop technological systems and applications that

\footnotetext{
${ }^{1}$ Applied Technology for Neuro-Psychology Lab.-ATN-P Lab., Istituto Auxologico Italiano, Milan, Italy.

${ }^{2}$ Interactive Communication and Ergonomics of NEw Technologies-ICE-NET Lab., Università Cattolica del Sacro Cuore, Milan, Italy.

${ }^{3}$ Dpto. Personalidad, Evaluación y Tratamientos Psicológicos, Universitat de València, Valencia, Spain.

${ }^{4}$ CIBER Fisiopatología Obesidad y Nutrición (CB06/03), Instituto de Salud Carlos III, Madrid, Spain.

${ }^{5}$ Dpto. Psicología Básica, Clínica y Psicobiología, Universitat Jaume I, Castellón, Spain.

${ }^{6}$ Virtual Reality Medical Institute, Brussels, Belgium.

${ }^{7}$ Virtual Reality Medical Center, San Diego, California.
} 
foster positive emotions, promote personal growth, and support creativity, thereby contributing to social and cultural development.

In the following sections, we propose the "Positive Technology" approach - the scientific and applied approach to the use of technology for improving the quality of our personal experience-as a way of framing a suitable object of study in the field of cyberpsychology and human-computer interaction. Specifically, we suggest that it is possible to use technology to enhance three specific features of our experience-affective quality, engagement/actualization, and connectedness-that serve to promote adaptive behaviors and positive functioning. Then, we identify Positive Technology foci and levels of analysis.

\section{Positive Psychology}

Positive Psychology is a nascent discipline whose broad goals are to understand human strengths and virtues, and to promote these strengths to allow individuals, communities, and societies to flourish. ${ }^{5-7}$ Martin Seligman, considered the father of this movement, pointed out how, subsequent to World War II, psychology became a science devoted to healing based on a disease model. However, it gradually became clearer to several scholars that this almost exclusive focus on pathology neglected the possibility of understanding normal and optimal functioning. This trend has resulted in a shift in emphasis toward the study of the factors that allow individuals and communities to thrive- the strengths' $^{\prime}$ perspective. ${ }^{8}$

\section{Philosophical and psychological perspectives on well-being}

What is happiness? As noted by many scholars, there is not an easy answer because the meaning of the question itself is unclear. However, philosophy has identified two different meanings for this concept: ${ }^{9}$ a state of mind (life satisfaction, pleasure, or a positive emotional condition); and a life that goes well for the person leading it. If we focus on this second meaning, "Happiness in this sense concerns what benefits a person, is good for her, makes her better off, serves her interests, or is desirable for her for her sake (well-being). ${ }^{\prime 9}$

But what is well-being? According to Parfit, ${ }^{10}$ there are three different theories of well-being: hedonism, desire theories, and objective list theories.

- Hedonism: according to hedonists (e.g., the view expressed by Socrates and Protagoras in the Platonic dialogue "Protagoras"), human beings always act in pursuit of what they think will give them the greatest balance of pleasure over pain. In other words, hedonists identify well-being roughly with experiences of pleasure; ${ }^{11}$

- Desire theories: according to this view, the person's wellbeing is the overall level of desire-satisfaction in their life as a whole. In other words, desire theorists equate well-being with the satisfaction of one's desires; ${ }^{9,11}$

- Objective list theories: according to this approach, there are items, such as knowledge or friendship, constituting well-being that consist neither merely in pleasurable experience nor in desire-satisfaction. ${ }^{11}$

Hedonism and desire theories are subjective approaches: well-being is grounded in the individual's subjective states. Objective list theorists, by contrast, are objective: some things benefit us independently of our attitudes or feelings. The most known example of this approach are Aristotelians. In their view, well-being (eudaimonia) is a life of virtuous activity-or more broadly, the fulfillment of our human capacities. ${ }^{9}$

These philosophical traditions have influenced the psychological reflections about well-being, too. Specifically, in Positive Psychology, we can find two different conceptions of well-being, namely "subjective well-being" (also called "hedonic well-being") and "psychological well-being" (also called "eudaimonic well-being"). The first position refers to a person's subjective evaluation of his life satisfaction and of his positive and negative emotional feelings. In contrast with subjective well-being, psychological well-being links happiness with lifelong conduct aimed at self-development. ${ }^{12}$ Whereas psychological well-being focuses on the challenges faced by adults in their private lives, social well-being concerns the tasks encountered by adults in their social structures and communities. ${ }^{13}$

\section{Integrating the Levels of Analysis: Toward a Positive Technology}

In the previous paragraph, we described the goals and the contents of Positive Psychology. Here, we suggest that it is possible to combine the objectives of Positive Psychology with enhancements of Information and Communication Technologies (ICTs) toward a new paradigm: Positive Technology. The final aim is to use technology to manipulate and enhance the features of our personal experience with the goal of increasing wellness, and generating strengths and resilience in individuals, organizations, and society. Specifically, in the following paragraph, we suggest an integrative framework of analysis based on the concept of "personal experience."

\section{The psychology of personal experience}

What is personal experience? According to the Merriam Webster Dictionary, ${ }^{14}$ it is possible to define it both as "a) direct observation of or participation in events as a basis of knowledge" and "b) the fact or state of having been affected by or gained knowledge through direct observation or participation." These definitions clearly underline the two faces of personal experience: if we can intentionally control the contents of our personal experience, its contents define our future intentions. In other words, we both shape and are shaped by it.

Moreover, not all the personal experiences are the same. Cognitive psychology has shown how the characteristics of our personal experience are influenced by the degree of perceptual stimulation, the meanings and values attributed, and the emotions elicited by it. ${ }^{15}$ So, we can have relevant experiences, positive or negative, that we remember for all our life, and experiences that we forget as soon as they end. Further, most of our experiences are cultural and interpersonal activities where individual experience is connected and/or mediated by collective experience. ${ }^{15}$

Finally, clinical psychology has clearly shown that personal change occurs through an intense focus on a particular experience. ${ }^{16}$ By exploring this experience as thoroughly as possible, the subject can relive all of the significant elements associated with it and make them available for reorganization. 
In sum, these features suggest that it is possible to manipulate the quality of experience with the goal of increasing wellness, and generating strengths and resilience in individuals, organizations, and society. But how is it possible to achieve this goal?

Seligman in his book Authentic Happiness identified "three pillars" of the good life: ${ }^{17}$

- The pleasant life: achieved through the presence of positive emotions;

- The engaged life: achieved through engagement in satisfying activities and utilization of one's strengths and talents;

- The meaningful life: achieved through serving a purpose larger than oneself.

More recently, Seligman introduced the PERMA model, an acronym for the five pillars of well-being: Positive emotions, Engagement, Relationships, Meaning, and Accomplishment. ${ }^{18}$

Following a similar view, Keyes and Lopez argued that positive functioning is a combination of three types of well- being: (a) high emotional well-being, (b) high psychological well-being, and (c) high social well-being. ${ }^{19}$

In other words, Positive Psychology identifies three characteristics of our personal experience-affective quality, engagement/actualization, and connectedness-that serve to promote personal well-being. In the proposed framework, positive technologies will be classified according to their effects on these three features of personal experience (see Figure 1):

- Hedonic: technologies used to induce positive and pleasant experiences;

- Eudaimonic: technologies used to support individuals in reaching engaging and self-actualizing experiences;

- Social/Interpersonal: technologies used to support and improve social integration and/or connectedness between individuals, groups, and organizations.

For each level, we will try to identify critical variables that can be manipulated and controlled to design and develop a Positive Technology.

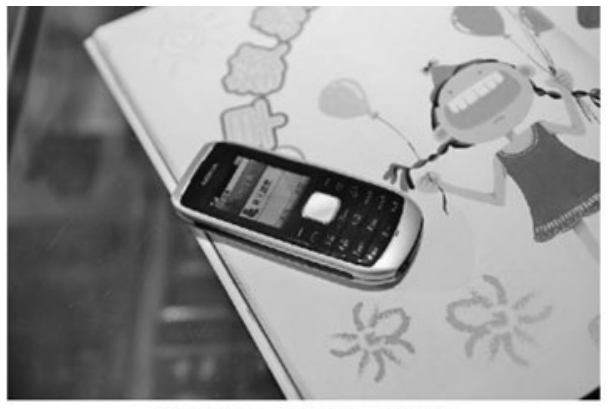

Positive Technology

The scientific and applied approach to the use of technology for improving the quality of our personal experience through its structuring, augmentation and/or replacement

\section{Experiential features targeted by technology}

Link with Well-Being

Related ICT topics
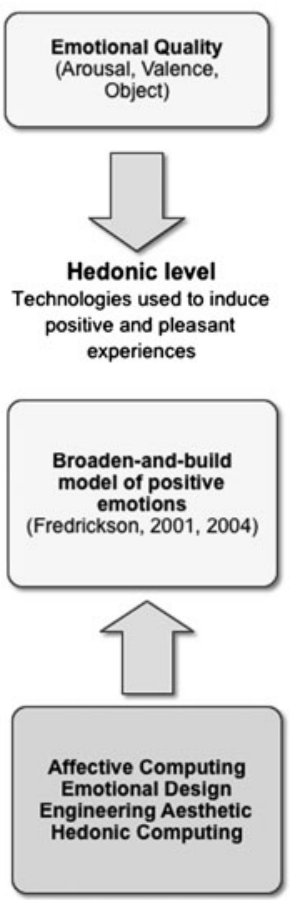

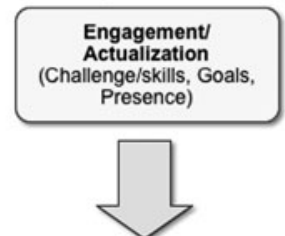

Eudaimonic level Technologies used to support individuals in reaching engaging and self-actualizing experiences

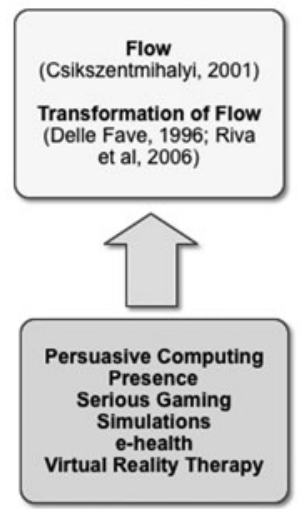

Connectedness Collective Intentions, Social Presence, Empathy)

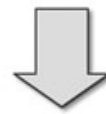

Social \& Interpersonal level

Technologies used to support and improve social integration and connectedness

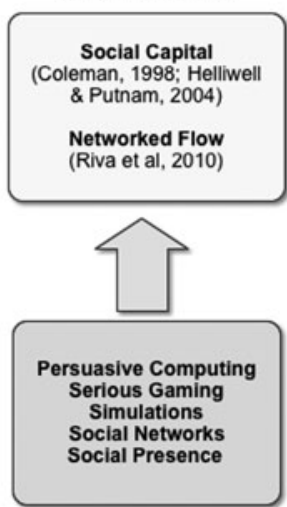

FIG. 1. The Positive Technology domain. 
Hedonic level: Using technology to foster positive emotions

The first dimension of Positive Technology concerns how to use technology to foster positive emotional states. In recent years, there has been an intensified discussion toward the role of emotions in human-computer interaction. This interest is expressed by emerging trends such as engineering aesthetics $^{20}$ and hedonic computing. ${ }^{21}$ A common feature of these approaches is the emphasis on the importance of understanding how interfaces should be designed to elicit positive emotional experiences from users.

According to the model of emotions developed by James Russell $^{22}$ it is possible to modify the affective quality of an experience through the manipulation of "core affect," a neurophysiological category corresponding to the combination of valence and arousal levels that endow the subjects with a kind of "core knowledge" about the emotional features of their experience (see Table 1).

The "core affect" can be experienced as freefloating (mood) or attributed to some cause (and thereby begins an emotional episode). In this view, an emotional response is the attribution of a change in the core affect given to a specific object (affective quality).

Simply put, a positive emotion is achieved by increasing the valence (positive) and arousal (high) of core affect (affect regulation) and by attributing this change to the contents of the proposed experience (object).

For instance, Riva and colleagues ${ }^{23}$ manipulated interactive media, in particular virtual reality (VR), using this approach to induce specific emotional responses, including positive moods. The results suggested the efficacy of VR as an affective medium: the interaction with "anxious" and "relaxing" virtual environments produced anxiety and relaxation.

Table 1. The "Core Affect" Model (AdAPTED From RusSell, 2003) $^{22}$

Concept Definition

Core Affect

A neurophysiological state that is consciously accessible as a simple, nonreflective feeling that is an integral blend of hedonic (pleasure-displeasure) and arousal. Core Affect responds to both real and virtual experiences.

Affective Quality The ability to cause a change in Core Affect.

Attributed Affect Core Affect attributed to an Object. This process, which is isolated from any judgment of the reality of the Object, is typically quick and automatic but can be deliberate.

Affect Regulation Action aimed directly at altering Core Affect. This process does not rely on the Object.

Object The person, condition, thing, or event at which a mental state is directed. An Object is a psychological representation, and therefore mental states can be directed at fictions, the future, and other forms of virtuality.
In a subsequent study, Villani and colleagues ${ }^{24,25}$ compared the efficacy of structured experiences provided through different technologies (video, audio, and VR) for inducing relaxing states. Results of this experiment showed a significant reduction of anxiety and a significant improvement in positive emotional states, measured through selfreport questionnaires and physiological parameters, but no difference among the media conditions. However, findings highlighted a significant correlation between changes in emotional states and factors related to the sense of presence felt by participants during media exposure.

Key arguments for the usefulness of positive emotions in increasing well-being have been recently provided by Fredrickson" 26,27 in what she called the "broaden-and-build model" of positive emotions. According to Fredrickson, positive emotions provide the organism with nonspecific action tendencies that can lead to adaptive behavior. ${ }^{26}$ For example, in children, joy is associated with the urge to play, whereas interest sparks the urge to explore; in adults, positive emotions make them more likely to interact with others, provide help to others in need, and engage in creative challenges. The second proposition of Fredrickson's model concerns the consequences of the positive emotions: by broadening an individual's awareness and thought-action repertoire, they build upon the resultant learning to create future physical, psychological, and social resources. ${ }^{27}$

\section{The eudaimonic level: Using technology to promote engagement and self-empowerment}

As we have seen, the first level of Positive Technology-the hedonic one-is concerned with the use of technologies to induce positive and pleasant experiences. The second level is more concerned with the eudaimonic concept of well-being, and consists of investigating how technologies can be used to support individuals in reaching engaging and self-actualizing experiences. Scholars in the field of human-computer interaction are starting to recognize and address this challenge. For example, Rogers ${ }^{28(\mathrm{p} 406)}$ calls for a shift from "proactive computing" to "proactive people," where "technologies are designed not to do things for people but to engage them more actively in what they currently do."

The theory of flow, developed by Positive Psychology pioneer Mihaly Csikszentmihalyi, ${ }^{29}$ provides a useful framework for addressing this challenge. Flow, or optimal experience, is a positive and complex state of consciousness that is present when individuals act with total involvement. The basic feature of this experience is the perceived balance between high environmental opportunities for action (challenges) and adequate personal resources in facing them (skills). Additional characteristics are deep concentration, clear rules in and unambiguous feedback from the task at hand, loss of self-consciousness, control of one's actions and environment, positive affect, and intrinsic motivation.

The theory of flow has been extensively used to study user experience with information and communication technologies (see Finneran and Zhang $^{30}$ for a comprehensive review of these studies). Ghani ${ }^{31}$ identified three factors that influence the occurrence of flow in human-computer interaction: perceived control, fitness of task (i.e., the difference between challenges and skills), and cognitive spontaneity ("playfulness"). According to Ghani's model, the experience of flow 
can produce positive cognitive effects in users, such as an augmented focus on the process, increased creativity, and enhanced learning. Other HCI scholars have focused on the investigation of the specific characteristics of optimal experience in computer-mediated communication activities, including Web-navigation, ${ }^{32,33}$ computer hacking, ${ }^{34,35}$ learning to use professional resources on the Web, ${ }^{36,37}$ and playing online games. ${ }^{34}$ In the context of interaction design, Pace $^{37}$ has defined specific guidelines about how to create Web sites that encourage optimal experience. These suggestions include: exploiting curiosity; being conscious of time urgency; matching challenges to the skills of users; focusing attention with relevant, interesting content; avoiding distracting interface elements; and enhancing discovery with surprise.

Among the different types of interactive technologies investigated so far by flow researchers, immersive systems such as VR are considered the most capable of supporting the emergence of this experience. ${ }^{38-40}$ Research conducted thus far highlights some key characteristics of this technology as a source of flow: (a) opportunities for action (goals and rules) - due to its flexibility, VR provides designers with the possibility of creating a wide range of increasingly challenging situations and tasks; (b) feedback-VR systems can offer multimodal feedback to individuals' actions and behavior. ${ }^{40,41}$ Some researchers have drawn parallels between the experience of flow in VR and the sense of presence, defined as the subjective perception of "being there" in a virtual environment. ${ }^{42-46}$ From the phenomenological viewpoint, both experiences have been described as absorbing states, characterized by a merging of action and awareness, loss of self-consciousness, a feeling of being transported into another reality, and an altered perception of time. ${ }^{47}$ Further, both presence and optimal experience are associated with high involvement, focused attention, and high concentration on the ongoing activity. ${ }^{48,49}$ In particular, Riva and Waterworth ${ }^{45,47}$ have argued that there is a cor- respondence between "maximal" presence and optimal experience. Drawing on Damasio's ${ }^{50}$ three-fold model of self (proto-self, core-self, and extended self), these authors have suggested that "optimal presence" arises when the three components of the self are combined with an abnormally tight focus on the same content (Table 2), so that intentions and action are directed exclusively toward the current external situation.

Starting from these theoretical premises, Riva and colleagues ${ }^{38,51}$ have suggested the possibility of using VR for a new breed of applications in positive mental health, based on a strategy defined as "transformation of flow," defined as a person's ability to draw upon an optimal experience induced by technology, and use it to promote new and unexpected psychological resources and sources of involvement.

This strategy, which integrates the Fredrickson's "broadenand-build model" with "flow" theory, involves three main steps. ${ }^{38,52}$ First, it is necessary to identify an information-rich environment that contains functional real-world demands; second, to use the technology to enhance the level of presence of the subject in the environment and to induce an optimal experience; third, to allow cultivation, by linking this optimal experience to the actual experience of the subject. As underlined by Gaggioli and colleagues, ${ }^{40}$ to maintain the balance between high challenges and skills that characterize optimal experience, the individual will search for increasingly complex opportunities for action, leading to the progressive improvement of related skills. By virtue of this dynamic process of skills cultivation and increasing levels of challenges, optimal experience influences individual development through the building of a life theme, namely the set of goals and interests a person preferentially pursues and cultivates in his/ her life.

The concept of transformation of flow holds significant promise for Positive Technology applications of VR and mobile devices. ${ }^{53,54}$ For example, Reid ${ }^{52}$ developed an integrated model of presence, playfulness, and flow in

Table 2. The Presence Model (Adapted from Riva et Al., 2011) ${ }^{45}$

\begin{tabular}{|c|c|}
\hline Concept & Definition \\
\hline Presence & $\begin{array}{l}\text { The intuitive (non-reflective) perception of successfully transforming our own intentions in action. } \\
\text { Although presence is a unitary feeling, on the process side it can be divided into three different } \\
\text { layers/subprocesses, phylogenetically different, and strictly related to the evolution of self. }\end{array}$ \\
\hline Proto Presence & $\begin{array}{l}\text { The first subprocess of Presence is related to the emergence of proto-self (Damasio }{ }^{51} \text { ): the intuitive } \\
\text { perception of successfully differentiating the self from the external world through action. It depends } \\
\text { on the level of perception-action coupling (Self vs. non-Self). }\end{array}$ \\
\hline Core Presence & $\begin{array}{l}\text { The second subprocess of Presence is related to the emergence of core-self (Damasio }{ }^{51} \text { ): the intuitive } \\
\text { perception of successfully acting in the external world toward a present Object. It depends on the } \\
\text { level of vividness (Self vs. Present External World). }\end{array}$ \\
\hline Extended Presence & $\begin{array}{l}\text { The third subprocess of Presence is related to the emergence of extended-self (Damasio }{ }^{51} \text { ): the intuitive } \\
\text { perception of successfully acting in the external world toward a possible Object. It depends on the } \\
\text { level of relevance (Self vs. Possible External World). }\end{array}$ \\
\hline Object & $\begin{array}{l}\text { The person, condition, thing, or event at which an action is directed. An Object is a psychological } \\
\text { representation, and therefore actions can be directed either at objects of the world (present Objects) or } \\
\text { fictions, the future, and other forms of virtuality (possible Objects). }\end{array}$ \\
\hline Flow & $\begin{array}{l}\text { There are exceptional situations-e.g., a tennis player that goes to the right (proto presence) before the } \\
\text { ball bounces on the court to swing a winning forehand ground stroke (core presence) on a second } \\
\text { setpoint at the Wimbledon final (extended presence)-in which the activity of the subject is } \\
\text { characterized by a high level of presence in all the three different subprocesses (Maximal Presence). } \\
\text { When this experience is associated with a positive emotional state, it constitutes a flow state. }\end{array}$ \\
\hline
\end{tabular}


rehabilitation. The model hypothesizes that flow and playfulness (expressed as being able to feel presence with the activity) are strictly related to volition and self-efficacy, and that VR has the potential to provide disabled persons with greater control over events in their environment, thereby enhancing a sense of competence and satisfaction with life. At the same time, virtual environments can be designed to offer highly motivating and challenging situations, facilitating active engagement of individuals with disabilities in the occupation of play.

In one study, Miller and Reid investigated the degree of motivation of children with cerebral palsy during VR play sessions. ${ }^{52}$ Results showed that different virtual environments were associated with varying degrees of volition, and that the key features of the most motivating play scenarios included challenge, variability, and competition.

\section{The social and interpersonal level: Using technology to promote social integration and connectedness}

The final level of Positive Technology-the social and interpersonal one-is concerned with the use of technologies to support and improve the connectedness between individuals, groups, and organizations. However, an open challenge is to understand how to use technology to create a mutual sense of awareness, which is essential to the feeling that other participants are there, and to create a strong sense of community at a distance. Short et al. ${ }^{55(\mathrm{p} 65)}$ define "social presence" as the "degree of salience of the other person in a mediated communication and the consequent salience of their interpersonal interactions." Conventional computermediated communicative tools, such as e-mail or text-based chat, are regarded as having lower social presence and social context cues when compared to face-to-face communication. However, different authors have suggested that it is possible to manipulate the technological experience to enhance social presence and thereby improve different mediated activities ${ }^{56}$ such as online learning, ${ }^{57}$ e-commerce, ${ }^{58}$ and healthcare. ${ }^{59}$

Riva and colleagues ${ }^{60}$ recently suggested that a subject is present within a virtual group if he is able to put his own intentions (presence) into practice and to understand the intentions of the other group members (social presence). This implies that, to sustain social optimal experiences (networked flow), the technology has to provide the virtual group with the possibility of expressing itself and of understanding what each individual member is doing. ${ }^{61}$ Moreover, Gaggioli and colleagues ${ }^{62}$ argued that optimal group state is achieved when the team develops a "weintention," in which the actions of the individuals and of the collective are merged, and the group acts as an autonomous, self-organizing entity (Table 3).

Following this vision, Morris ${ }^{63}$ has recently described how social networking and pervasive computing technologies can be effectively used to help reduce feelings of social isolation and depression in elderly individuals. In his approach, sensor data measuring phone calls and visits are used to derive public displays of social interactions with relatives and

Table 3. The Networked Flow Model (Adapted from Gaggioli et Al., 2011) ${ }^{62}$

Concept Definition

Networked Flow

Meeting/Persistence

Reducing the Distance

The Liminality-Parallel Action

Optimal Experience

Creation of the Artifact

Sharing of the Artifact

Social Presence
A peak creative state that is achieved when members of a team experience high levels of presence and social presence in their common activity. It is a six-staged process, which begins with the co-construction of a shared frame and culminates with the creation of a novel artifact or concept.

The first phase in the emergence of networked flow, Persistence, can take place in any social environment in which there are a certain number of individuals who share an interactive context. The members are able to understand the reciprocal intentions directed toward the present time.

In this second phase, something new happens: the perception of similarities between the people who share the same direction of the intention-vector. Individuals, having perceived these similarities, tend to prefer to interact with each other (creation of a subgroup) and to become aware of more and more similarities between them and in their motivations.

In this third phase, the newly created subgroup, after reducing the distance, begins to consolidate its "boundaries" with respect to the pre-existing frame, and to identify a common "intention-vectors" (collective intention) in a direction which enables the subgroup to close in on the perceived limits of the pre-existing frame.

By transforming the collective intention into a collective action, the subgroup enters into an "optimal" collective experience. In this phase, the existing frame is abandoned, and a new frame, which provides a more valid background in which to support the group's creative activity, is established.

During this phase, the subgroup "substantiate" its common activity in the form of an artifact (meme) originating from the collective action. This artifact—an object, a thought, a theory, a custom - is then adopted by the members of the group in their daily activity, and this represents a further element of differentiation from the previous frame.

In the final phase, the subgroup tries to share the new artifact and its embedded collective intention with the pre-existing frame and other groups.

The intuitive (non-reflective) perception of successfully understanding the intentional action of another self. 
friends, which they introduced into selected elders' homes. These ambient displays, which reflect data on remote and face-to-face interaction gathered by wireless sensor networks, are intended to raise awareness of social connectedness as a dynamic and controllable aspect of well-being. According to his findings, this strategy was effective in reducing the feeling of social isolation of elderly users.

Key arguments for the usefulness of connectedness in increasing well-being have been presented by Ryff and Singer. ${ }^{64}$ The authors argued that interpersonal flourishing (the development of positive relations with other people) is a key dimension of well-being, which is stable across different cultures and across time. Moreover, in a recent paper, Mauri and colleagues ${ }^{65}$ used different physiological data-skin conductance, blood volume pulse, electroencephalogram, electromyography, respiratory activity, and pupil dilationto evaluate the affective experience evoked by the use of Facebook. The biological signals revealed that Facebook use can evoke a psychophysiological state characterized by high positive valence and high arousal (Core Flow State). These findings support the hypothesis that the successful spread of social networks might be associated with a specific positive affective state experienced by users when they use their account. Finally, the concept of "social capital" underlines the value of social relationships for the society as a whole: relations among persons facilitate action and promote wellbeing. ${ }^{66,67}$

Despite the fact that creating and maintaining social relationships is considered a major indicator of well-being and a protective factor for health, ${ }^{68}$ Western society is characterized by increasing levels of loneliness and lack of social integration. The need of social integration is higher in specific social groups, such as adolescents, disabled, and elderly people. As a consequence, healthcare policies have become increasingly interested in supporting mental health and rehabilitation programs aimed at overcoming social isolation. Information and communication technologies can play a key role in improving these programs.

\section{Conclusions}

A significant part of the discussions related to the use of technology in our life starts with the same question: "What is wrong with technology?" This question, in all its possible formats, has guided the reflections of technology developers, designers, ergonomists, HCI experts, and psychologists during the last 60 years. Given the many shortcomings of the available digital tools, this question has produced a neverending discussion around technology's "dark side."

During the workshop "Virtual Reality and Advanced ICT in Europe," held at the recent Medicine Meets Virtual Reality (MMVR) conference in Newport Beach, California February 8-12, 2011, ${ }^{69}$ the authors of this paper introduced a different question: "What is right about technology?" This question is at the heart of the "Positive Technology" approach, which is the scientific and applied approach to the use of technology for improving the quality of our personal experience.

The core psychological background of "Positive Technology" is "Positive Psychology" a nascent discipline whose broad goals are to understand the human strengths and virtues, and to promote these strengths to allow individuals, communities, and societies to flourish. Specifically, Positive Psychology views optimal functioning as the combination of emotional well-being, social well-being, and psychological well-being.

In this paper, we suggest that it is possible to use technology to manipulate the quality of experience, with the goal of increasing wellness, and generating strengths and resilience in individuals, organizations, and society. The examples presented show that technology can be used to manipulate the features of an experience in three separate but related ways:

- By structuring it using a goal, rules, and a feedback system. ${ }^{70}$ The goal provides subjects with a sense of purpose focusing attention and orienting his/her participation in the experience. The rules, by removing or limiting the obvious ways of getting to the goal, push subjects to see the experience in a different way. The feedback system tells individuals how close they are to achieving the goal and provides motivation to keep trying.

- By augmenting it to achieve multimodal and mixed experiences. Technology allows multisensory experiences in which content and its interaction are offered through more than one of the senses. It is even possible to use technology to overlay virtual objects onto real scenes. ${ }^{71}$

- By replacing it with a synthetic one. Using VR, it is possible to simulate physical presence in a synthetic world that reacts to the action of the subject as if he/she was really there. Moreover, the replacement possibilities offered by technology even extend to the induction of an illusion of ownership over a virtual arm or a virtual body. $^{72}$

Additionally, we have classified positive technologies according to their effects on these three features of personal experience:

- Hedonic: technologies used to induce positive and pleasant experiences;

- Eudaimonic: technologies used to support individuals in reaching engaging and self-actualizing experiences;

- Social/Interpersonal: technologies used to support and improve the connectedness between individuals, groups, and organizations.

Finally, for each level, we have identified critical variablesaffect regulation for the hedonic one, flow and presence for the eudaimonic one; social presence, collective intentions, and networked flow for the social/interpersonal one-that can be manipulated and controlled to guide the design and development of positive technologies.

In this same issue of CYBER, Botella et al. ${ }^{73}$ further define this view by discussing the links between existing technologies and the Positive Technology framework described here. For now, we welcome you to Positive Technology.

\section{Acknowledgments}

This work was partially funded by the INTERSTRESS (FP7-247685; www.interstress.eu) and OPTIMI (FP7-248544; www.optimiproject.eu) European research funded projects. It is also supported by the following projects: Generalitat Valenciana, PROMETEO (2008/157); CIBER Fisiopatología de la Obesidad y Nutrición is an initiative of ISCIII. 


\section{Disclosure Statement}

No competing financial interests exist.

\section{References}

1. Amichai-Hamburger Y. (ed.) (2009) Technology and psychological well-being. Cambridge, UK: Cambridge University Press.

2. Zhang P, Li N, Scialdone M, et al. The intellectual advancement of human-computer interaction research: A critical assessment of the MIS literature (1990-2008). AIS Transactions on Human-Computer Interaction 2009; 1:55-107.

3. Zhang P, Benbasat I, Carey J, et al. Human-computer interaction research in the MIS discipline. Communications of the AIS 2002; 9:334-55.

4. Sander T. (2011) Positive computing. In Biswas-Diener R, ed. Positive psychology as social change. London: Springer, pp. 309-26.

5. Seligman MEP, Csikszentmihalyi M. Positive psychology. American Psychologist 2000; 55:5-14.

6. Snyder CR, Lopez SJ, Teramoro Pedrotti J. (2011) Positive psychology: The scientific and practical explorations of human strengths. 2nd ed. Thousand Oaks, CA: Sage.

7. Aspinwall LG, Staudinger UM (eds.) (2003) A psychology of human strengths: Fundamental questions and future directions for a positive psychology. Washinton, DC: APA Books.

8. Lambert MJ, Erekson DM. Positive psychology and the humanistic tradition. Journal of Psychotherapy Integration 2008; 18:222-32.

9. Haybron D. (2011) Happiness. In Zalta EN, ed. The Stanford encyclopedia of philosophy. Fall 2011 ed. Stanford, CA: Stanford University Press. http://plato.stanford.edu/archives/ fall2011/entries/happiness/ (accessed Sept. 19, 2011).

10. Parfit D. (1984) Reasons and persons. Oxford: Oxford University Press.

11. Crisp R. (2008) Well-being. In Zalta EN, ed. The Stanford encyclopedia of philosophy. Winter 2008 ed. Stanford, CA: Stanford University Press. http://plato.stanford.edu/archives/win2008/ entries/well-being/ (accessed Sept. 19, 2011).

12. Waterman AS. Two conceptions of happiness: Contrasts of personal expressiveness (eudaimonia) and hedonic enjoyment. Journal of Personality \& Social Psychology 1993; 64:678-91.

13. Keyes CLM, Haidt J (eds.) (2003) Flourishing: Positive psychology and the life well-lived. Washington, DC: American Psychological Association.

14. Merriam-Webster. (2010) The Merriam-Webster dictionary. Springfield, MA: Merriam-Webster.

15. Goldstein EB. (2010) Cognitive psychology: Connecting mind, research and everyday experience. 3rd ed. Belmont, CA: Wadsworth.

16. Wolfe BE. The role of lived experience in self- and relational observation: A commentary on Horowitz (2002). Journal of Psychotherapy Integration 2002; 12:147-53.

17. Seligman MEP. (2002) Authentic happiness: Using the new positive psychology to realize your potential for lasting fulfillment. New York: Free Press.

18. Seligman MEP. (2001) Flourish: A visionary new understanding of happiness and well-being. New York: Free Press.

19. Keyes CLM, Lopez SJ. (2002) Toward a science of mental health: Positive directions in diagnosis and interventions. In Snyder CR, Lopez SJ, eds. Handbook of positive psychology. New York: Oxford University Press, pp. 45-59.

20. Liu Y. Engineering aesthetics and aesthetic ergonomics: Theoretical foundations and a dual-process research methodology. Ergonomics 2003; 46:1273-92.
21. Wakefield RL, Whitten D. Mobile computing: A user study on hedonic/utilitarian mobile device usage. European Journal of Information Systems 2006; 15:292-300.

22. Russell JA. Core affect and the psychological construction of emotion. Psychological Review 2003; 110:145-72.

23. Riva G, Mantovani F, Capideville CS, et al. Affective interactions using virtual reality: The link between presence and emotions. CyberPsychology \& Behavior 2007; 10:45-56.

24. Villani D, Riva F, Riva G. New technologies for relaxation: The role of presence. International Journal of Stress Management 2007; 14:260-74.

25. Villani D, Lucchetta M, Preziosa A, et al. The role of interactive media features on the affective response: A virtual reality study. eMind. International Journal on Human Computer Interaction 2009; 1:1-21.

26. Fredrickson BL. The role of positive emotions in positive psychology. The broaden-and-build theory of positive emotions. American Psychologist 2001; 56:218-26.

27. Fredrickson BL. The broaden-and-build theory of positive emotions. Philosophical Transactions of the Royal Society of London Series B Biological Sciences 2004; 359:1367-78.

28. Rogers Y. (2006) Moving on from Weiser's vision of of calm computing: Engaging UbiComp experiences. In Dourish P, Friday A, eds. Ubicomp 2006 Proceedings. Heidelberg: Springer-Verlag, pp. 404-21.

29. Csikszentmihalyi M. (1990) Flow: The psychology of optimal experience. New York: HarperCollins.

30. Finneran CM, Zhang P. Flow in computer-mediated environments: Promises and challenges. Communications of the Association for Information Systems 2005; 15:82-101.

31. Ghani JA. (1995) Flow in human-computer interactions: Test of a model. In Carey JM, ed. Human factors in information systems: Emerging theoretical bases. Norwood, NJ: Ablex, pp. 291-311.

32. Skadberg YX, Kimmel JR. Visitors' flow experience while browsing a Web site: Its measurement, contributing factors and consequences. Computers in Human Behavior 2004; 20:403-22.

33. Chen H, Wigand RT, Nilan M. Exploring Web users' optimal flow experiences. Information Technology \& People 2000; 13:263-81.

34. Voiskounsky AE. (2008) Flow experience in cyberspace: Current studies and perspectives. In Barak A, ed. Psychological aspects of cyberspace: Theory, research, applications. Cambridge, UK: Cambridge University Press, pp. 70-101.

35. Beveren JV. A conceptual model for Hacker development and motivations. Journal of E-Business 2001; 1:1-9.

36. Heidman L, Sharafi P. Early use of Internet-based educational resources: Effects on students' engagement modes and flow experience. Behaviour \& Information Technology 2004; 23:137-46.

37. Pace S. A grounded theory of the flow experiences of Web users. International Journal of Human-Computer Studies 2004; 60:327-63.

38. Riva G, Castelnuovo G, Mantovani F. Transformation of flow in rehabilitation: The role of advanced communication technologies. Behavior Research Methods 2006; 38:237-44.

39. Riva G, Algeri D, Pallavicini F, et al. The use of advanced technologies in the treatment of psychological stress. Journal of Cybertherapy \& Rehabilitation 2010; 2:169-71.

40. Gaggioli A, Bassi M, Delle Fave A. (2003) Quality of experience in virtual environments. In Riva G, IJsselsteijn WA, Davide F, eds. Being there: Concepts, effects and measurement of user presence in synthetic environment. Amsterdam: Ios Press, pp. 121-35. 
www.emergingcommunication.com/volume5.html (accessed Sept. 22, 2011).

41. Gaggioli A. (2004) Optimal experience in ambient intelligence. In Riva G et al., eds. Ambient intelligence: The evolution of technology, communication and cognition towards the future of human-computer interaction. Amsterdam: IOS Press, pp. 35-43. www.emergingcommunication.com/volume6.html (accessed Sept. 22, 2011).

42. Riva G, Waterworth JA, Waterworth EL. The layers of presence: A bio-cultural approach to understanding presence in natural and mediated environments. CyberPsychology \& Behavior 2004; 7:405-19.

43. Heeter C. Reflections on real presence by a virtual person. Presence: Teleoperators \& Virtual Environments 2003; 12:335-45.

44. Zahoric P, Jenison RL. Presence as being-in-the-world. Presence: Teleoperators, \& Virtual Environments 1998; 7:78-89.

45. Riva G, Waterworth JA, Waterworth EL, et al. From intention to action: The role of presence. New Ideas in Psychology $2011 ; 29: 24-37$.

46. Riva G. (2009) Presence as cognitive process. In Benyon D, Smyth M, \& Helgason I, eds. Presence for everyone: A short guide to presence research. Edinburgh, UK: Napier University, pp. 29-31.

47. Waterworth JA, Waterworth EL, Mantovani F, et al. On feeling (the) present: An evolutionary account of the sense of presence in physical and electronically-mediated environments. Journal of Consciousness Studies 2010; 17:167-78.

48. Klimmt C, Vorderer P. Media psychology "is not yet there": Introducing theories on media entertainment to the presence debate. Presence: Teleoperators \& Virtual Environments 2003; 12:346-59.

49. Marsh T. (2003) Staying there: An activity-based approach to narrative design and evaluation as an antidote to virtual corpsing. In Riva G, Davide F, IJsselsteijn WA, eds. Being there: Concepts, effects and measurements of user presence in synthetic environments. Amsterdam: IOS Press, pp. 85-96.

50. Damasio A. (1999) The feeling of what happens: Body, emotion and the making of consciousness. San Diego, CA: Harcourt Brace.

51. Riva G, Gaggioli A. (2009) Rehabilitation as empowerment: The role of advanced technologies. In Gaggioli A, Keshner EA, Weiss PL, Riva G, eds. Advanced technologies in rehabilitation: Empowering cognitive, physical, social and communicative skills through virtual reality, robots, wearable systems and braincomputer interfaces. Amsterdam: IOS Press, pp. 3-22.

52. Riva G, Mantovani F, Gaggioli A. Presence and rehabilitation: Toward second-generation virtual reality applications in neuropsychology. Journal of Neuroengineering \& Rehabilitation 2004; 8:1-9.

53. Baños R, Cebolla A, Zaragoza I, et al. Electronic PDA dietary and physical activity registers in a weight loss treatment program for children: A description of the etiobe personal digital assistant system. Journal of CyberTherapy \& Rehabilitation 2009; 2:235-42.

54. Pallavicini F, Algeri D, Repetto C, et al. Biofeedback, VR and mobile phones in the treatment of generalized anxiety disorder (Gad): A phase-2 controlled clinical trial. Journal of CyberTherapy \& Rehabilitation 2009; 2:315-28.

55. Short J, Williams E, Christie B. (1976) The social psychology of telecommunications. London: Wiley.

56. Park H. The effect of activities in virtual worlds as a communication environment to understand each other. Journal of CyberTherapy \& Rehabilitation 2010; 3:71-82.

57. Joyce KM. Enhancing social presence in online learning: Mediation strategies applied to social networking tools. Online Journal of Distance Learning Administration 2009; 12. www.westga.edu/ distance/ojdla/winter124/joyce124.html (accessed Sept. 22, 2011).

58. Swamynathan G, Wilson C, Boe B, et al. (2008) Do social networks improve e-commerce?: A study on social marketplaces. In First workshop on online social networks. New York: ACM.

59. Boulos MNK, Wheeler S. The emerging Web 2.0 social software: An enabling suite of sociable technologies in health and health care education. Health Information \& Libraries Journal 2007; 24:2-23.

60. Gorini A, Capideville CS, De Leo G, et al. The role of immersion and narrative in mediated presence: The virtual hospital experience. CyberPsychology, Behavior \& Social Networks 2011; 14:99-105.

61. Riva G. (2004) The psychology of ambient intelligence: Activity, situation and presence. In Riva G et al., eds. Ambient intelligence: The evolution of technology, communication and cognition towards the future of the human-computer interaction. Amsterdam: IOS Press, pp. 19-34. www.emergingcommunication.com/ volume6.html (accessed Sept. 22, 2011).

62. Gaggioli A, Milani L, Mazzoni E, Riva G. Networked flow: A framework for understanding the dynamics of creative collaboration in educational and training settings. The Open Education Journal 2011; 1:41-49.

63. Morris ME. Social networks as health feedback displays. IEEE Internet Computing 2005; 9:29-37.

64. Ryff CD, Singer B. Interpersonal flourishing: A positive health agenda for the new millennium. Personality \& Social Psychology Review 2000; 4:30-44.

65. Mauri M, Villamira M, Cipresso P, et al. Why is Facebook so successful? Psychophysiological measures describe a core flow state while using Facebook. CyberPsychology, Behavior, and Social Networking 2011; 14:723-731.

66. Helliwell JF, Putnam RD. The social context of well-being. Philosophical Transactions of the Royal Society of London Series B Biological Sciences 2004; 359:1435-46.

67. Coleman JS. Social capital in the creation of human capital. The American Journal of Sociology 1988; 94:S95S120.

68. House JS, Landis KR, Umberson D. Social relationships and health. Science 1988; 241:540-45.

69. Riva G, Banos R, Botella C, et al. Personal health systems for mental health: The European projects. Studies in Health Technology \& Informatics 2011; 163:496-502.

70. McGonical J. (2011) Reality is broken. Why games make us better and how they can change the world. New York: Penguin Press.

71. Rosenblum L. Virtual and augmented reality 2020. IEEE Computer Graphics \& Applications 2000; 20:38-9.

72. Slater M, Spanlang B, Sanchez-Vives MV, et al. First person experience of body transfer in virtual reality. PLoS One 2010; 5:e10564.

73. Botella C, Riva G, Gaggioli A, et al. The present and future of positive technologies. CyberPsychology, Behavior, and Social Networking 2012; 1:78-84.

Address correspondence to: Prof. Giuseppe Riva Department of Psychology Università Cattolica del Sacro Cuore Largo Gemelli 1 20123 Milan Italy

E-mail: giuseppe.riva@unicatt.it 
Copyright of CyberPsychology, Behavior \& Social Networking is the property of Mary Ann Liebert, Inc. and its content may not be copied or emailed to multiple sites or posted to a listserv without the copyright holder's express written permission. However, users may print, download, or email articles for individual use. 